\title{
STRUCTURAL SHAKEDOWN: A NEW METHODOLOGY FOR ESTIMATING THE RESIDUAL DISPLACEMENTS
}

\author{
Liudas LIEPA, Gediminas BLAŽEVIČIUS, Dovilè MERKEVIČIŪTĖ, Juozas ATKOČIŪNAS \\ Department of Structural Mechanics, Vilnius Gediminas Technical University, \\ Sauletekio al. 11, LT-10223 Vilnius, Lithuania
}

Received 10 Jun 2016; accepted 20 Jul 2016

\begin{abstract}
A vector of residual forces of the ideally elastic-plastic structure at shakedown is obtained by solving the static analysis problem. A unique distribution of the residual forces is determined if the analysis is based on the minimum complementary deformation energy principle. However, the residual displacements developing in the shakedown process of ideally elastic-plastic structures under variable repeated loads can vary non-monotonically. Nevertheless mathematical models for the optimization problems of steel structures at shakedown must include the conditions for strength (safety) and stiffness (serviceability). Residual displacements determined by the plastic deformations are included in the stiffness conditions; therefore to improve the optimal solution it is necessary to determine upper and lower bounds of the residual displacement variations. This paper describes an improved methodology for estimating the variation bounds of the residual displacements at shakedown.
\end{abstract}

Keywords: elastic-plastic structures, shakedown, unloading phenomenon, residual displacements, energy principles, mathematical programming.

\section{Introduction}

The classic term "structural shakedown" implies understanding that paper refers to the ideal elastic-plastic structures subjected to variable repeated load $\boldsymbol{F}(t)$ (vectors are denoted as bold letters) (Casciaro, Garcea 2002; Chaaba et al. 2010; Giambanco et al. 2004; Koiter 1960; König 1987; Maier 1969; Polizzotto et al. 1991; Raad, Weichert 1995; Staat, Heitzer 2003; Stein et al. 1992; Weichert, Maier 2002). Variable repeated load (VRL) is a system of external forces $\boldsymbol{F}(t)$, that may vary within time $t$ independently of each other. Load $\boldsymbol{F}(t)$ is assumed to be quasi-static, i.e. dynamic effects are ignored. VRL is defined by lower $\boldsymbol{F}_{\text {inf }}$ and upper $\boldsymbol{F}_{\text {sup }}$ variation bounds $\left(\boldsymbol{F}_{\text {inf }} \leq \boldsymbol{F}(t) \leq \boldsymbol{F}_{\text {sup }}\right)$. In this paper, the equilibrium finite element method based on internal force approximation is applied for the discretization of structures (taking in to account an assumption of small displacements) (Alawdin 2005; Belytschko 1972; Kalanta et al. 2009; Kaliszky, Lógó 2002; McGuire et al. 2000; Ngo, Tin-Loi 2007; Simon et al. 2013; Venskus et al. 2010). Optimization problems of elastic-plastic steel structures subjected to VRL are nonconvex mathematical programming problems (Atkočiūnas 2012; Rozvany 2011). Mathematical models for the optimization problems of steel structures at shakedown contains strength (safety) and stiffness (serviceability) conditions (Alawdin, Liepa
2016; Atkočiūnas, Venskus 2011; Kala 2005; Kaliszky, Lógó 2002; Merkevičiūtė, Atkočiūnas 2006; Palizzolo et al. 2014; EN 1993-1-1:2005). Displacements determined by plastic deformations appear in stiffness conditions. But the residual displacements developing during shakedown process of ideally elastic-plastic structures under variable repeated load can vary non-monotonically. Therefore, it is necessary to be able to determine upper $\boldsymbol{u}_{r \text {,sup }}$ and lower $\boldsymbol{u}_{r \text {,inf }}$ variation bounds of residual displacements and to connect them with pseudo-elastic displacements (Capurso 1974; Lange-Hansen 1998; Liepa, Gervyte 2015). In regards to mathematical models some for the limit and shakedown analysis of rod elements of reinforced concrete cross-section, involving the calculations of cross-section under quasi-static low-cycle loadings were presented by Alawdin and Kasabutski (2009). Modified mathematical model for optimization of reinforced concrete plane frames, subjected to variable repeated loads, at shakedown conditions was presented by Alawdin and Liepa (2015). In this paper, based on the principles of extreme energy (complementary and total potential energy minimum) (Tran 2011), a new scanning technique, which does not require detail analysis of loading history, is proposed for evaluation of residual displacements of structures at shakedown. 


\section{Structural discretization, main dependences}

The numerical methods of structural mechanics are based on a discrete structural model. The geometry of the structure, the material and finite element type are known. The equilibrium finite element method is applied for the discretization of a structure (Kalanta et al. 2012). The stress state of a discrete structure is expressed by the vector of forces $\boldsymbol{S}=\left[\begin{array}{llll}\boldsymbol{S}_{1} & \boldsymbol{S}_{2} & \ldots & \boldsymbol{S}_{\zeta}\end{array}\right]^{T}, \zeta=s \times v$, where $s$ is the number of finite elements $(k=1,2, \ldots, s, k \in K)$ and $v$ is the number of nodes (design sections) of each element $(l=1,2, \ldots, v, l \in L)$. Thus, overall, there are $\zeta=s \times v$ design sections: $i=1,2, \ldots, \zeta, i \in I$. In general, every section has several internal forces, therefore every component $\boldsymbol{S}_{i}$ of the vector $\boldsymbol{S}$ expresses a vector of these forces (e.g. the bending moments for plates or bending moment and axial force for a plane frame section). In this case, the total number of scalar components in the vector $\boldsymbol{S}$ is $n$, but because a section-wise description is more convenient for the general analysis of a discrete structure, section index $\zeta$ is kept as well (Atkočiūnas et al. 2015). Forces $\boldsymbol{S}_{k}(x)$ at any point $x$ of finite element $k$ are expressed via forces $\boldsymbol{S}_{k}$ of element nodal points, using approximation matrix $\boldsymbol{H}_{k}(x)$ : $\boldsymbol{S}_{k}(x)=\left[\boldsymbol{H}_{k}(x)\right] \boldsymbol{S}_{k}$. The degree of freedom of a model is $m$, thus vectors of global displacements $\boldsymbol{u}$ and load $\boldsymbol{F}$ are $\boldsymbol{u}=\left[\begin{array}{llll}u_{1} & u_{2} & \ldots & u_{m}\end{array}\right]^{T}$ and $\boldsymbol{F}=\left[\begin{array}{llll}F_{1} & F_{2} & \ldots & F_{m}\end{array}\right]^{T}$, respectively. Nodal deformations are grouped together in vector $\Theta=\left[\begin{array}{llll}\Theta_{1} & \Theta_{2} & \ldots & \Theta_{\zeta}\end{array}\right]^{T}$.

In order to avoid analyzing loading history the authors use all possible discrete combinations of external loading $\quad \boldsymbol{F}_{j}: \boldsymbol{F}_{\text {inf }} \leq \boldsymbol{F}_{j} \leq \boldsymbol{F}_{\text {sup }}, \quad j=1,2, \ldots, p, p=2^{m}$ $j \in J$. Then elastic forces $\boldsymbol{S}_{e j}=\left[\begin{array}{llll}\boldsymbol{S}_{e j, 1} & \boldsymbol{S}_{e j, 2} & \ldots & \boldsymbol{S}_{e j, \zeta}\end{array}\right]^{T}$ and displacements $\boldsymbol{u}_{e j}=\left[\begin{array}{llll}u_{e j, 1} & u_{e j, 2} & \ldots & u_{e j, m}\end{array}\right]^{T}$ are determined using the influence matrices $\boldsymbol{\alpha}$ and $\boldsymbol{\beta}$ :

$$
\boldsymbol{S}_{e j}=\boldsymbol{\alpha} \boldsymbol{F}_{j}, \boldsymbol{u}_{e j}=\boldsymbol{\beta} \boldsymbol{F}_{j}, j \in J .
$$

At shakedown state the total response due to a particular load combination contains elastic and residual components: $\boldsymbol{S}_{j}=\boldsymbol{S}_{e j}+\boldsymbol{S}_{r} ; \boldsymbol{u}_{j}=\boldsymbol{u}_{e j}+\boldsymbol{u}_{r}$. Residual forces $\boldsymbol{S}_{r}=\left[\begin{array}{llll}\boldsymbol{S}_{r, 1} & \boldsymbol{S}_{r, 2} & \ldots & \boldsymbol{S}_{r, \zeta}\end{array}\right]^{T}$ are self-balanced:

$$
\boldsymbol{A} \boldsymbol{S}_{r}=\mathbf{0} .
$$

Where $\boldsymbol{A}(m \times n)$ is the matrix of the coefficients of equilibrium equations. Strength (yield) condition is verified in every design section $i \in I$, for every load combination $j \in J: \varphi_{i j}=S_{0 i}-f_{i j}\left(\boldsymbol{S}_{e j, i}+\boldsymbol{S}_{r, i}\right) \geq 0$. Yield conditions for the whole structure are as follows:

$$
\boldsymbol{\varphi}_{j}=\boldsymbol{C}-\boldsymbol{f}_{j}\left(\boldsymbol{S}_{e j}+\boldsymbol{S}_{r}\right) \geq \mathbf{0}, j \in J .
$$

Plastic constants in these conditions are element limiting forces $\boldsymbol{C} \equiv \boldsymbol{S}_{0}$ which are assumed to be constant over the whole finite element. Statically admissible residual forces $\boldsymbol{S}_{r}$ satisfy the equilibrium Eqns (2) and the yield conditions (3).

Residual displacements $\boldsymbol{u}_{r}=\left[\begin{array}{llll}u_{r, 1} & u_{r, 2} & \ldots & u_{r, m}\end{array}\right]^{T}$ satisfy geometric equations:

$$
\boldsymbol{A}^{T} \boldsymbol{u}_{r}=\boldsymbol{\Theta}_{r}, \quad \Theta_{r}=\boldsymbol{D} \boldsymbol{S}_{r}+\Theta_{p},
$$

where $\Theta_{p}=\left[\Theta_{p, 1} \Theta_{p, 2} \ldots \Theta_{p, \zeta}\right]^{T}=\left[\Theta_{p, 1} \Theta_{p, 2} \ldots \Theta_{p, n}\right]^{T}$ is a vector of plastic deformations and $\boldsymbol{\Theta}_{r}=\boldsymbol{D} \boldsymbol{S}_{r}+\boldsymbol{\Theta}_{p}$ are residual deformations $\boldsymbol{\Theta}_{r}=\left[\boldsymbol{\Theta}_{r, 1} \Theta_{r, 2} \ldots \Theta_{r, \zeta}\right]^{T}=$ $\left[\Theta_{r, 1} \Theta_{r, 2} \ldots \Theta_{r, n}\right]^{T}$. Here $\boldsymbol{D}(n \times n)$ is a blockdiagonal matrix of element flexibilities $\boldsymbol{D}_{k}$. The components of the vector of plastic deformations $\Theta_{p}$ are calculated according to the equation:

$\Theta_{p}=\left(\Theta_{p, i}\right)^{T}, \Theta_{p, i}=\sum_{j}\left[\nabla \varphi_{i j}\left(\boldsymbol{S}_{e j, i}+\boldsymbol{S}_{r, i}\right)\right]^{T} \lambda_{i j}$,

$\lambda_{i j} \geq \mathbf{0}, \quad i \in I, \quad j \in J$.

Here the expression

$$
\left[\nabla \varphi_{i j}\left(\boldsymbol{S}_{e j, i}+\boldsymbol{S}_{r, i}\right)\right]^{T}=\left[\frac{\partial f_{i j}\left(\boldsymbol{S}_{e j, i}+\boldsymbol{S}_{r, i}\right)}{\partial \boldsymbol{S}_{r, i}}\right]
$$

is a gradient matrix of yield conditions (3) and $\lambda_{i j}$ is a vector of plastic multipliers. Kinematically admissible residual displacements $\boldsymbol{u}_{r}$ satisfy geometric Eqns (4) and kinematic boundary conditions.

\section{Static formulation of the shakedown analysis problem}

Variation bounds $\boldsymbol{F}_{\text {inf }}, \boldsymbol{F}_{\text {sup }}$ of the load $\boldsymbol{F}(t)$, ensuring structural shakedown, are known. Vector of residual forces $\boldsymbol{S}_{r}$ of the discrete structure at shakedown is obtained by solving the formulated static analysis problem. This formulation is written on the basis of the minimum complementary deformation energy principle (Atkočiūnas 2012): of all statically admissible vectors $\boldsymbol{S}_{r}$ of residual forces, the actual one corresponds to the minimum of complementary deformation energy of the structure at shakedown. For the structure at shakedown, complementary deformation energy $\mathcal{F}^{\prime}$ is expressed in terms of residual forces as follows: $\mathcal{F}^{\prime}\left(\boldsymbol{S}_{r}\right)=\frac{1}{2} \boldsymbol{S}_{r}^{T} \boldsymbol{D} \boldsymbol{S}_{r}$. In this case, the following extreme problem corresponds to the principle:

$$
\operatorname{minimize}\left(\mathcal{F}^{\prime}\left(\boldsymbol{S}_{r}\right)=\frac{1}{2} \boldsymbol{S}_{r}^{T} \boldsymbol{D} \boldsymbol{S}_{r}\right)=a^{*},
$$

subject to

$$
\begin{gathered}
A \boldsymbol{S}_{r}=\mathbf{0}, \\
\boldsymbol{\varphi}_{j}=\boldsymbol{C}-\boldsymbol{f}_{j}\left(\boldsymbol{S}_{e j}+\boldsymbol{S}_{r}\right) \geq \mathbf{0} \text { for all } j \in J .
\end{gathered}
$$


In problem (7)-(9), vector of limiting forces $\boldsymbol{C} \equiv \boldsymbol{S}_{0}$ and pseudo-elastic internal forces $\boldsymbol{S}_{e j}, j \in J$ are known quantities. Vector of statically admissible residual forces $\boldsymbol{S}_{r}$ is unknown, which minimizes the objective function (7). Matrix $\boldsymbol{D}$ is defined positively, therefore function $\mathcal{F}^{\prime}$ is convex. Non-linear yield conditions (9) are convex functions. Problem (7)-(9) belongs to the group of convex non-linear mathematical problems (Bazaraa et al. 2006). Thus, an optimal solution to the static formulation of the analysis problem at shakedown (7)-(9) is unique and will be denoted by $\boldsymbol{S}_{r}^{*}$. It is important to note, that after problem (7)-(9) is solved, for example using MATLAB, not only optimal solution $\boldsymbol{S}_{r}^{*}$ is obtained, but also optimal solutions $\boldsymbol{u}_{r}^{*}$ and $\lambda_{j}^{*}$ of dual problem are found. Having determined plastic multipliers $\lambda_{j}^{*}$, it is possible to calculate plastic deformations $\Theta_{p}^{*}=\sum_{j}\left[\nabla \boldsymbol{f}_{j}\left(\boldsymbol{S}_{e j}+\boldsymbol{S}_{r}^{*}\right)\right]^{T} \lambda_{j}^{*}$ according to Eqn

(without solving kinematic formulation of analysis problem directly). But mathematical model (7)-(9) is only good for analyzing of shakedown process, when unloading phenomenon of cross-sections does not appear (more details about unloading phenomenon will be presented in Section 5.4).

\section{Complete equation system of analysis problem for structures at shakedown}

The constraints of problem (7)-(9), together with KuhnTucker conditions constitute the complete system of equations defining the stress-strain state of the structure at shakedown (Euler-Lagrange problem):

$$
\begin{gathered}
\boldsymbol{A} \boldsymbol{S}_{r}=\mathbf{0} \\
\boldsymbol{C}-\boldsymbol{f}_{j}\left(\boldsymbol{S}_{e j}+\boldsymbol{S}_{r}\right) \geq \mathbf{0} \\
\boldsymbol{D} \boldsymbol{S}_{r}+\sum_{j}\left[\nabla \boldsymbol{f}_{j}\left(\boldsymbol{S}_{e j}+\boldsymbol{S}_{r}\right)\right]^{T} \lambda_{j}-\boldsymbol{A}^{T} \boldsymbol{u}_{r}=\mathbf{0} ; \\
\lambda_{j}^{T}\left[\boldsymbol{C}-\boldsymbol{f}_{j}\left(\boldsymbol{S}_{e j}+\boldsymbol{S}_{r}\right)\right]=0 ; \\
\lambda_{j} \geq \mathbf{0} \text { for all } j \in J .
\end{gathered}
$$

If $\boldsymbol{S}_{e j}$ and $\boldsymbol{C}$ are known, solution of system (10)-(14) is $\boldsymbol{S}_{r}^{*}, \boldsymbol{u}_{r}^{*}, \boldsymbol{\lambda}_{j}^{*}$. As it was mentioned earlier, it is not difficult to calculate plastic deformations $\boldsymbol{\Theta}_{p}^{*}$ according to Eqn (5) and express (or check) residual displacements $\boldsymbol{u}_{r}^{*}$ and forces $\boldsymbol{S}_{r}^{*}$ :

$$
\begin{gathered}
\boldsymbol{u}_{r}^{*}=\left[\left(\boldsymbol{A} \boldsymbol{D}^{-1} \boldsymbol{A}^{T}\right)^{-1} \boldsymbol{A} \boldsymbol{D}^{-1}\right] \boldsymbol{\Theta}_{p}^{*}=\overline{\boldsymbol{H}} \boldsymbol{\Theta}_{p}^{*} \\
\boldsymbol{S}_{r}^{*}=\left[\boldsymbol{D}^{-1} \boldsymbol{A}^{T}\left(\boldsymbol{A} \boldsymbol{D}^{-1} \boldsymbol{A}^{T}\right)^{-1} \boldsymbol{A} \boldsymbol{D}^{-1}-\boldsymbol{D}^{-1}\right] \boldsymbol{\Theta}_{p}^{*}=\overline{\boldsymbol{G}} \boldsymbol{\Theta}_{p}^{*} \\
\boldsymbol{\Theta}_{p}^{*}=\sum_{j}\left[\nabla \boldsymbol{f}_{j}\left(\boldsymbol{S}_{e j}+\boldsymbol{S}_{r}^{*}\right)\right]^{T} \boldsymbol{\lambda}_{j}^{*}
\end{gathered}
$$

$$
\begin{gathered}
\boldsymbol{C}-\boldsymbol{f}_{j}\left(\boldsymbol{S}_{e j}+\boldsymbol{S}_{r}^{*}\right) \geq \mathbf{0} ; \\
\lambda_{j}^{* T}\left[\boldsymbol{C}-\boldsymbol{f}_{j}\left(\boldsymbol{S}_{e j}+\boldsymbol{S}_{r}^{*}\right)\right]=0 ; \\
\lambda_{j}^{*} \geq \mathbf{0} \text { for all } j \in J .
\end{gathered}
$$

Here $\overline{\boldsymbol{G}}$ and $\overline{\boldsymbol{H}}$ are the influence matrices of residual forces $\boldsymbol{S}_{r}^{*}$ and displacements $\boldsymbol{u}_{r}^{*}$ accordingly. It is not difficult to calculate $\boldsymbol{S}_{r}^{*}=\overline{\boldsymbol{G}} \boldsymbol{\Theta}_{p}^{*}$ and $\boldsymbol{u}_{r}^{*}=\overline{\boldsymbol{H}} \boldsymbol{\Theta}_{p}^{*}$ when plastic deformations $\boldsymbol{\Theta}_{p}^{*}$ are known. Equations (15), (16) are valid not only for $\boldsymbol{\Theta}_{p}^{*}$, but also for plastic deformations $\tilde{\Theta}_{p}^{*}$, obtained analyzing shakedown process, when unloading phenomenon manifests.

Example 1. The known geometry two-span frame structure is considered (Fig. 1). Bending stiffness $E I$ and axial stiffness $E A$ of elements are known (where $E=205.0 E+06$ - elastic modulus of steel, $\mathrm{kPa} ; I=25.17 E-05$ - crosssectional moment of inertia of standard HEB300 crosssection, $\mathrm{m}^{4} ; A=149.0 E-04$ - cross-sectional area, $\mathrm{m}^{2}$ ). Limit bending moment $M_{0}=\sigma_{y} W_{p l}$ and limiting axial force $N_{0}=\sigma_{y} A$ of frame members are known (where $\sigma_{y}=253.2 E+03-$ yielding stresses of steel, $\mathrm{kPa}$, $W_{p l}=1869.0 E-06$ - plastic section modulus, $\mathrm{m}^{3}$ ), see Figure 1a. The frame is subjected to variable repeated loading, i.e. two concentrated forces $F_{1}(t)$ and $F_{2}(t)$, varying in time, are applied and their variation bounds are $0 \leq F_{1}(t) \leq 341.0 \mathrm{kN}$ and $0 \leq F_{2}(t) \leq 440.0 \mathrm{kN}$. Shakedown analysis problem (7)-(9) is solved (using MATLAB): it is determined if the frame under given loading shakes down and if so, the residual forces $\boldsymbol{S}_{r}^{*}$, ensuring shakedown process, plastic deformations $\theta_{p}^{*}$ and residual displacements $\boldsymbol{u}_{r}^{*}$ are obtained.

Discrete model of the frame is made by using 14 sections $(i=1,2, \ldots, \zeta=14, i \in I)$ and 7 finite elements $(k=1,2, \ldots, s=7, k \in K)$. Each of the elements may experience two bending moments (one in each section) and one axial force: there are three internal forces per element in total. Thus, the total number of components of internal force vector $S$ is $n=21$ :

$$
\begin{aligned}
& \boldsymbol{S}=\left[\begin{array}{llllllllll}
S_{1} & S_{2} & S_{3} & S_{4} & S_{5} & S_{6} & \ldots & S_{19} & S_{20} & S_{21}
\end{array}\right]^{T}=
\end{aligned}
$$

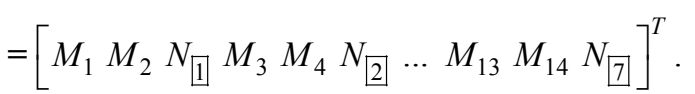

For frame, equilibrium equations $\boldsymbol{A S}=\boldsymbol{F}$ are written using equilibrium finite elements: the $\operatorname{rank}(17 \times 21)$ of the coefficient matrix $\boldsymbol{A}$ is obtained ( $m=17, n=21)$. Vector of residual forces $\boldsymbol{S}_{r}$ consists from 21 components and equilibrium conditions (8) of shakedown analysis problem (7)-(9) takes traditional form $\boldsymbol{A S}_{r}=\mathbf{0}$. Physical meaning of each column of matrix $\boldsymbol{A}$ is determined by the composition of vector (21). Equilibrium equations are written following the order of global displacements (Fig. 1b). 

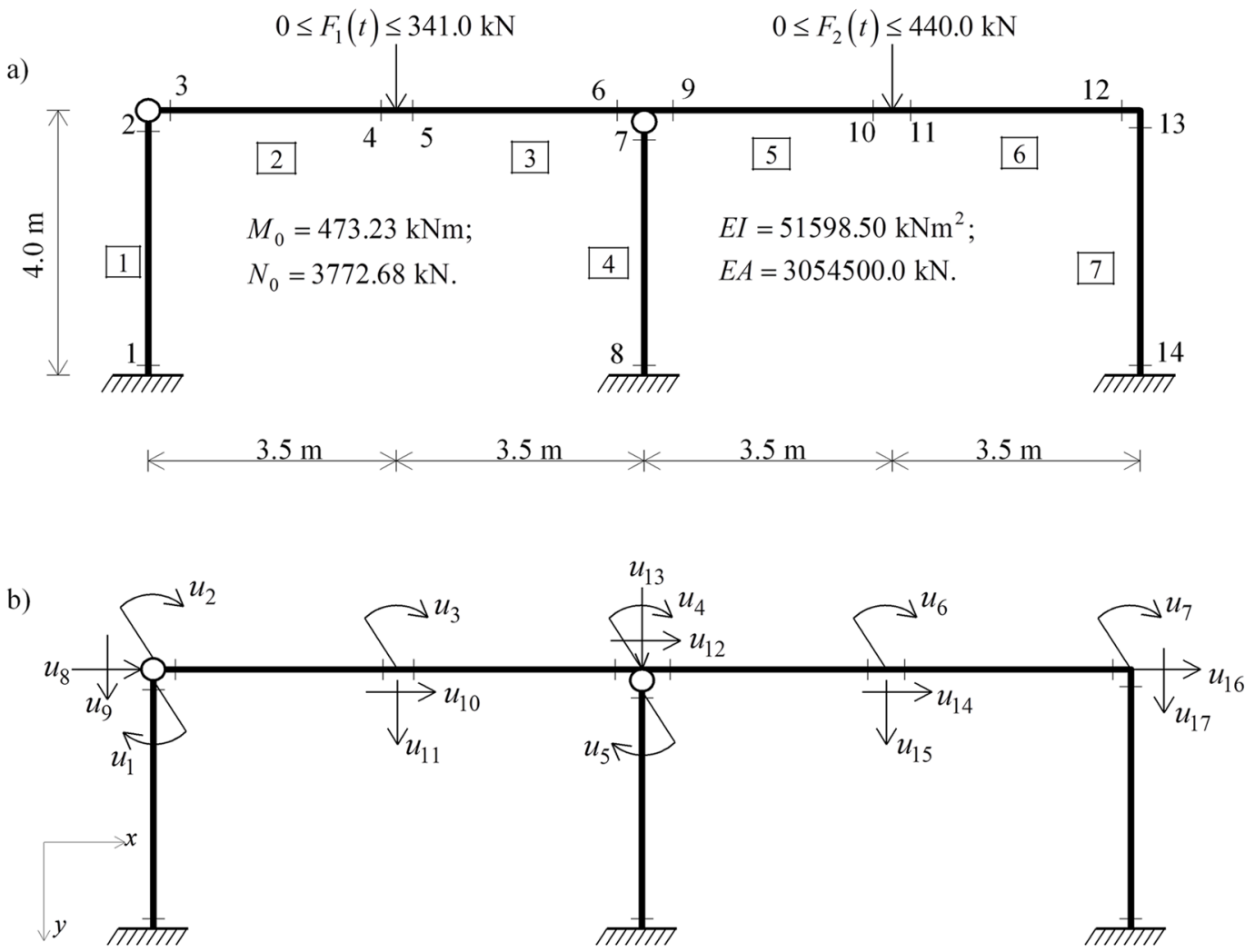

Fig. 1. A discrete model of the two-span frame subjected to the variable repeated loads (element numbers are marked in square ): a) calculation scheme, b) scheme of possible nodal displacements directions (DOF is $m=17$ )

Linear yield conditions

(1) $M_{e i}+M_{r i}-M_{o i} \leq 0$,

(2) $M_{e i} / 1.18+c_{i} N_{e i}+M_{r i} / 1.18+c_{i} N_{r i}-M_{o i} \leq 0$,

(3) $M_{e i} / 1.18-c_{i} N_{e i}+M_{r i} / 1.18-c_{i} N_{r i}-M_{o i} \leq 0$,

(4) $-M_{e i}-M_{r i}-M_{o i} \leq 0$,

(5) $-M_{e i} / 1.18+c_{i} N_{e i}-M_{r i} / 1.18+c_{i} N_{r i}-M_{o i} \leq 0$,

(6) $-M_{e i} / 1.18-c_{i} N_{e i}-M_{r i} / 1.18-c_{i} N_{r i}-M_{o i} \leq 0$ )

are checked for every $i$-th section $(i \in I)$. The coefficient in the Eqn (22) is $c_{i}=M_{0 i} / N_{0 i}$. With 6-dimensional limiting moment vector having constant values for a particular finite element $\boldsymbol{M}_{0 i}=\left[M_{0 i} M_{0 i} \ldots M_{0 i}\right]^{T}$, yield conditions $\boldsymbol{\varphi}_{i}$ (22) for $i$-th section are written as follows:

$$
\boldsymbol{\varphi}_{i}=\boldsymbol{\Phi}_{i}\left(\boldsymbol{S}_{e i}+\boldsymbol{S}_{r i}\right)-\boldsymbol{M}_{0 i} \leq \mathbf{0} .
$$

Here matrix $\boldsymbol{\Phi}_{i}$ for $i$-th cross-section is expressed as follows:

$$
\boldsymbol{\Phi}_{i}=\left[\begin{array}{cc}
1 & 0 \\
1 / 1.18 & c_{i} \\
1 / 1.18 & -c_{i} \\
-1 & 0 \\
-1 / 1.18 & c_{i} \\
-1 / 1.18 & -c_{i}
\end{array}\right] .
$$

And limiting bending moment is constant $M_{0}=\sigma_{y} W_{p l}=473.23 \mathrm{kNm}$ (see Fig. 1a).

Component number of load vector corresponds to degree of freedom $m$ of frame discrete model. When there are less non-zero forces acting, it is convenient to include only non-zero components into vector $\boldsymbol{F}$, for example, $\boldsymbol{F}=\left[F_{1} F_{2}\right]^{T}$ for frame shown in Figure 1. Having done that for considered frame (Fig. 1), the three main apexes $j$ of load $\boldsymbol{F}(t)=\left[F_{1}(t) F_{2}(t)\right]^{T}$ (see Table 1).

The first load combination $j=1$ allows to write vector $\boldsymbol{F}_{1}=\left[\begin{array}{ll}341.0 & 0\end{array}\right]^{T}$, the second one $j=2$ gives $\boldsymbol{F}_{2}=\left[\begin{array}{ll}0 & 440.0\end{array}\right]^{T}$ and the third one $(j=3)$ $\boldsymbol{F}_{3}=\left[\begin{array}{ll}341.0 & 440.0\end{array}\right]^{T}$. Having used two corresponding (11th and 15th according to Fig. 1b) columns $\boldsymbol{\alpha}_{1-2}$ of the influence matrix of internal forces $\alpha$, it is possible to calculate vectors of elastic internal forces $\boldsymbol{S}_{e 1}=\boldsymbol{\alpha}_{1-2} \boldsymbol{F}_{1}$, $\boldsymbol{S}_{e 2}=\boldsymbol{\alpha}_{1-2} \boldsymbol{F}_{2}, \boldsymbol{S}_{e 3}=\boldsymbol{\alpha}_{1-2} \boldsymbol{F}_{3}$ according to Eqn (1). Calculated values are presented in Table 1 . Numbers and types of internal force vector components are presented in the first two columns of the Table 1 according to the formation of vector (21). It becomes clear that, for determining fact of frame's ability to shake down (adapt) to given load, yield conditions (23) are written for every apex $j, j \in J$ of force locus (domain): 


$$
\left\{\begin{array}{l}
\boldsymbol{\varphi}_{i, j=1}=\boldsymbol{\Phi}_{i}\left(\boldsymbol{S}_{e i, j}+\boldsymbol{S}_{r i}\right)-M_{0 i} \leq \mathbf{0}, \\
\boldsymbol{\varphi}_{i, j=2}=\boldsymbol{\Phi}_{i}\left(\boldsymbol{S}_{e i, j}+\boldsymbol{S}_{r i}\right)-M_{0 i} \leq \mathbf{0}, \\
\boldsymbol{\varphi}_{i, j=3}=\boldsymbol{\Phi}_{i}\left(\boldsymbol{S}_{e i, j}+\boldsymbol{S}_{r i}\right)-\boldsymbol{M}_{0 i} \leq \mathbf{0} .
\end{array}\right.
$$

At the beginning of the analysis problem (7)-(9) solution process using MATLAB, it becomes clear that there exists at least one statically admissible vector of residual forces $\boldsymbol{S}_{r}$, i.e. frame adapts to load $0 \leq F_{1} \leq 341.0 \mathrm{kN}$ and $0 \leq F_{2} \leq 440.0 \mathrm{kN}$ (yield conditions are not violated - there is no cyclic-plastic collapse). Optimal solution $\boldsymbol{S}_{r}^{*}$ of the analysis problem (7)-(9) is presented in Table 1. It should be emphasized that analysis problem (7)-(9) is solved once for the combination of forces $\boldsymbol{F}_{1, \text { sup }}=341.0, \boldsymbol{F}_{2 \text {,sup }}=440.0$. Solution of dual problem is $\boldsymbol{\lambda}_{j}^{*}$ (or $\boldsymbol{\Theta}_{p}^{*}$, see Table 1 ) and $\boldsymbol{u}_{r}^{*}$. For every section, deformations $\Theta_{p}^{*}$ are calculated according to Eqn (5)

$$
\begin{aligned}
& \Theta_{p i}^{*}= \sum_{j} \Phi_{i}^{T} \lambda_{i j}^{*}, i \in I, j \in J: \\
& \Theta_{p}^{*}=\left[\begin{array}{lllllll}
\Theta_{p 1}^{*} & \Theta_{p 2}^{*} & \Theta_{p 3}^{*} & \ldots & \Theta_{p 19}^{*} & \Theta_{p 20}^{*} & \Theta_{p 21}^{*}
\end{array}\right]^{T} .
\end{aligned}
$$

Solution of the analysis problem (7)-(9), given in the table 1 , is further analyzed. It is convenient to link vector $\boldsymbol{S}_{r}^{*}$ with Eqn (16) $\boldsymbol{S}_{r}^{*}=\overline{\boldsymbol{G}} \boldsymbol{\Theta}_{p}^{*}$. Residual forces $\boldsymbol{S}_{r}^{*}$ obtained according to Eqn (16) coincides with optimal solution presented in Table 1. Influence matrix of residual forces $\overline{\boldsymbol{G}}$ is square: its rows correspond to the composition of force vector (21) and columns are related to the deformation vector (26).

It is necessary to note, that Eqn (16) is not the only way to check residual forces $\boldsymbol{S}_{r}^{*}$. That can be done by solving optimization problem as follows:

$$
\operatorname{minimize}\left\{\frac{1}{2} \boldsymbol{S}_{r}^{T} \boldsymbol{D} \boldsymbol{S}_{r}+\boldsymbol{S}_{r}^{T} \boldsymbol{\Theta}_{p}^{*}\right\},
$$

subjected to

$$
\boldsymbol{A} \boldsymbol{S}_{r}=\mathbf{0} .
$$

Where vector of plastic deformations $\boldsymbol{\Theta}_{p}^{*}$ is known and residual forces are to be found. Optimal solution of problem (27)-(28) are residual forces that completely coincides with the ones presented in Table 1 .

Like it was mentioned above, dual solution of analysis problem (7)-(9) also includes the residual displacements $\boldsymbol{u}_{r}^{*}, \mathrm{~m}$ :

$\boldsymbol{u}_{r}^{*}=\left[\begin{array}{lllll}-0.0021 & -0.0002 & -5.20 E-05 & 0.000392 & -0.00212\end{array}\right.$

$-0.00997-0.00426-0.00561-1.60 E-06-0.00563-0.00053$

$\left.\begin{array}{lllll}-0.00564 & -1.0 E-05 & -0.00568 & 0.025925-0.00571 & 1.88 E-05\end{array}\right]^{T}$.

Physical meaning of displacement vector compo-

\begin{tabular}{|c|c|c|c|c|c|}
\hline No. Type & $\boldsymbol{S}_{e, j=1}$ & $\boldsymbol{S}_{e, j=2}$ & $\boldsymbol{S}_{e, j=3}$ & $\boldsymbol{S}_{r}^{*}$ & $\Theta_{p}^{*}$ \\
\hline $1 \quad M_{1}$ & -31.5251 & 123.946 & 92.42117 & 54.3023 & 0 \\
\hline $2 \quad M_{2}$ & 0 & 0 & 0 & 0 & 0 \\
\hline $3 \quad N_{\text {[1 }}$ & -136.382 & 32.2406 & -104.141 & 1.2455 & 0 \\
\hline $4 \quad M_{3}$ & 0 & $4.88 \mathrm{E}-14$ & $4.88 \mathrm{E}-14$ & 0 & 0 \\
\hline $5 \quad M_{4}$ & -477.336 & 112.842 & -364.494 & 4.35919 & 0 \\
\hline $6 \quad N_{\text {[ }}$ & 7.881286 & -30.9866 & -23.1053 & -13.5756 & 0 \\
\hline $7 \quad M_{5}$ & 477.336 & -112.842 & 364.4938 & -4.35919 & 0 \\
\hline $8 \quad M_{6}$ & 238.8281 & 225.684 & 464.5124 & 8.71837 & 0 \\
\hline $9 \quad N_{\sqrt[3]{3}}$ & 7.881286 & -30.9866 & -23.1053 & -13.5756 & 0 \\
\hline $10 M_{7}$ & $-1.90 \mathrm{E}-14$ & $4.88 \mathrm{E}-14$ & $2.99 \mathrm{E}-14$ & $-1.7 \mathrm{E}-32$ & 0 \\
\hline $11 M_{8}$ & -31.6999 & 124.633 & 92.93345 & 54.6033 & 0 \\
\hline $12 N_{\text {近 }}$ & -247.81 & -248.806 & -496.616 & 13.1388 & 0 \\
\hline $13 \quad M_{9}$ & -238.828 & -225.684 & -464.512 & -8.7183 & -0.00616 \\
\hline $14 M_{10}$ & 87.65557 & -532.294 & -444.639 & 59.0634 & -0.01889 \\
\hline $15 N_{[5}$ & 15.80626 & -62.1449 & -46.3387 & -27.2264 & 0 \\
\hline $16 M_{11}$ & -87.6556 & 532.2942 & 444.6386 & -59.0634 & 0 \\
\hline $17 M_{12}$ & -63.5169 & 249.7272 & 186.2103 & 109.408 & 0 \\
\hline 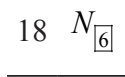 & 15.80626 & -62.1449 & -46.3387 & -27.226 & 0 \\
\hline $19 M_{13}$ & 63.51691 & -249.727 & -186.21 & -109.408 & 0 \\
\hline $20 M_{14}$ & -0.29188 & 1.147573 & 0.855694 & 0.5028 & 0 \\
\hline $21 N_{\text {田 }}$ & 43.19214 & -223.435 & -180.243 & -14.3843 & 0 \\
\hline
\end{tabular}
nents is associated with frame scheme (see Fig. 1 b).
Table 1. Elastic internal forces for each apex of load locus $j=1$, $j=2, j=3$ and results of problem (7)-(9) for frame shown in Figure 1

\section{Scanning procedure of load locus and analysis problem for a stage}

\subsection{Scanning procedure}

Load variation bounds $\boldsymbol{F}_{\text {inf }}, \boldsymbol{F}_{\text {sup }}$ and the limiting forces $\boldsymbol{M}_{0}$ are known. The scanning method is based on the extension of the variation locus of external forces (Fig. 2). 


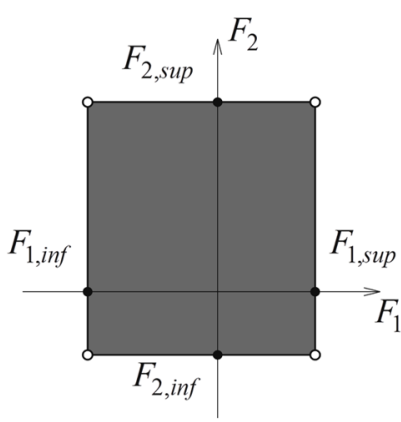

a)

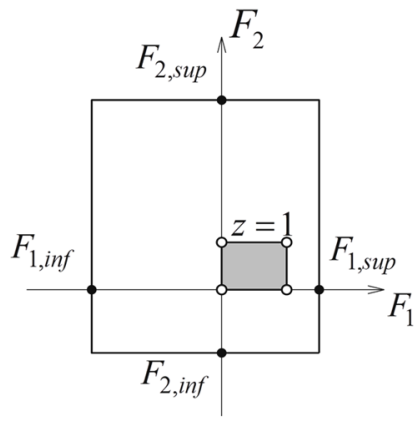

b)

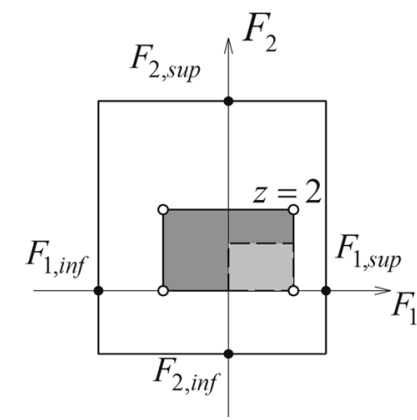

c)

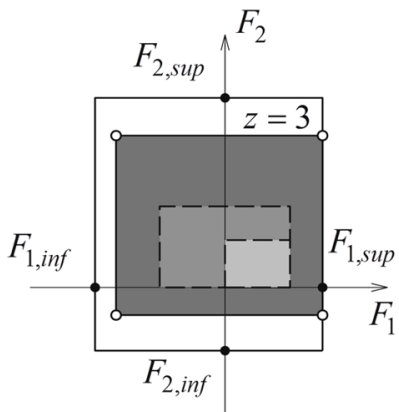

d)

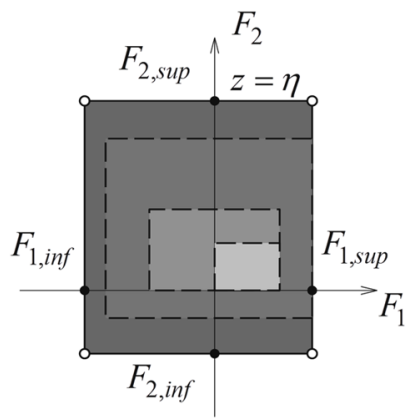

e)

Fig. 2. Typical scanning procedure: a) variation locus of load $\boldsymbol{F}_{\text {sup }}, \boldsymbol{F}_{\text {inf }}$; b) 1st scanning stage; c) 2nd scanning stage; d) 3rd scanning stage; e) $\eta$-th scanning stage (returning to the "a)" - full load locus)

One of the procedures for scanning the locus of varying loads is employed through $z(z=1,2, \ldots, \eta$, $z \in Z$ ) stages. For every $z$ stage of scanning, a new locus of varying loads $\boldsymbol{F}_{j}^{z}$ covering the previous locus $\boldsymbol{F}_{j}^{z-1}, j \in J$ is formed. Then analysis problem (7)-(9) is solved recording all possible distributions of plastic deformations. An important point is that every scanning stage does not require making new influence matrices $\boldsymbol{\alpha}$ and $\boldsymbol{\beta}$ (this would be impossible incrementally investigating particular loading history $\boldsymbol{F}(t)$ ). Then, for every stage are obtained:

$$
\boldsymbol{S}_{\boldsymbol{e} j}^{z}=\boldsymbol{\alpha} \boldsymbol{F}_{j}^{z}, \quad \boldsymbol{u}_{e j}^{z}=\boldsymbol{\beta} \boldsymbol{F}_{j}^{z}, j \in J, \quad z \in Z .
$$

\subsection{Scanning procedure: first formulation of analysis problem}

Using Eqn (29) $\boldsymbol{S}_{\boldsymbol{e} j}^{z}=\boldsymbol{\alpha} \boldsymbol{F}_{j}^{z}$ for the scanning procedure, analysis problem (7)-(9) obtains following form for each scanning stage $z \quad(z \in Z)$ :

$$
\operatorname{minimize}\left(\mathcal{F}^{\prime}\left(\boldsymbol{S}_{r}^{z}\right)=\frac{1}{2} \boldsymbol{S}_{r}^{z T} \boldsymbol{D} \boldsymbol{S}_{r}^{z}\right)=a^{\mathbf{z}^{*}}
$$

subject to

$$
\begin{gathered}
\boldsymbol{A} \boldsymbol{S}_{r}^{z}=\mathbf{0}, \\
\boldsymbol{\varphi}_{j}^{z}=\boldsymbol{C}-\boldsymbol{f}_{j}\left(\boldsymbol{S}_{e j}^{z}+\boldsymbol{S}_{r}^{z}\right) \geq \mathbf{0} \quad j \in J, z \in Z .
\end{gathered}
$$

Optimal solution of the problem (30)-(32) is $\boldsymbol{S}_{r}^{z^{*}}$. Solution of the dual problem to (30)-(32) are $\boldsymbol{\Theta}_{p}^{z *}$ and $\boldsymbol{u}_{r}^{z *}$. Using Eqns (15) and (16) it is convenient to verify relations between obtained solutions: $\boldsymbol{S}_{r}^{z^{*}}=\overline{\boldsymbol{G}} \boldsymbol{\Theta}_{p}^{z *}$ and $\boldsymbol{u}_{r}^{z^{*}}=\overline{\boldsymbol{H}} \boldsymbol{\Theta}_{p}^{z *}$. Thus, for $z=\eta$, solution $\boldsymbol{S}_{r}^{z^{*}}$ of the problem (30)-(32) completely coincides with optimal solution $\boldsymbol{S}_{r}^{*}$ of the problem (7)-(9) (see Table 1). Mathematical model (30)-(32) enables to determine possible unloading phenomenon of cross-sections within limits of chosen scanning strategy.

\subsection{Scanning procedure: second formulation of analysis problem}

In this case, substitution of variables is introduced in the analysis problem (30)-(32): $\boldsymbol{S}_{r}^{z}=\boldsymbol{S}_{r \Sigma}^{z-1}+\Delta \boldsymbol{S}_{r}^{z}$, where $\Delta \boldsymbol{S}_{r}^{z}$ is increment of residual forces $\boldsymbol{S}_{r}$ at the end of each scanning stage $\boldsymbol{F}_{j}^{z}(z \in Z, j \in J)$ (increment $\Delta \boldsymbol{S}_{r}^{z}$ is caused by load change from $\boldsymbol{F}_{j}^{z-1}$ to $\left.\boldsymbol{F}_{j}^{z}\right)$. Further in the paper $\boldsymbol{S}_{r}^{z}$ will be noted $\boldsymbol{S}_{r \Sigma}^{z}\left(\boldsymbol{S}_{r}^{z} \equiv \boldsymbol{S}_{r \Sigma}^{z}\right)$ to emphasize the summation procedure. Meanwhile $\boldsymbol{S}_{r \Sigma}^{z-1}$ is sum of increments of residual forces obtained in earlier stages for the beginning of $z$-th stage:

$$
\boldsymbol{S}_{r \Sigma}^{z-1}=\Delta \boldsymbol{S}_{r}^{0}+\Delta \boldsymbol{S}_{r}^{1}+\ldots+\Delta \boldsymbol{S}_{r}^{z-1}=\sum_{z} \Delta \boldsymbol{S}_{r}^{z-1} .
$$

When $z=1$, initial increment $\Delta \boldsymbol{S}_{r}^{0}=\mathbf{0}$ and $\boldsymbol{S}_{r \Sigma}^{0}=\mathbf{0}$. Then for each scanning stage $z(z \in Z)$ using elastic forces $\boldsymbol{S}_{\boldsymbol{e} j}^{z}=\boldsymbol{\alpha} \boldsymbol{F}_{j}^{z}$, following analysis problem is solved: 


$$
\min \left(\begin{array}{l}
\mathcal{F}^{\prime}\left(\boldsymbol{S}_{r \Sigma}^{z-1}+\Delta \boldsymbol{S}_{r}^{z}\right)= \\
\frac{1}{2}\left(\boldsymbol{S}_{r \Sigma}^{z-1}+\Delta \boldsymbol{S}_{r}^{z}\right)^{T} \boldsymbol{D}\left(\boldsymbol{S}_{r \Sigma}^{z-1}+\Delta \boldsymbol{S}_{r}^{z}\right)
\end{array}\right)=a^{\mathbf{z}^{*}},
$$

subject to

$$
\begin{gathered}
\boldsymbol{A} \Delta \boldsymbol{S}_{r}^{z}=\mathbf{0} \\
\boldsymbol{\varphi}_{j}^{z}=\boldsymbol{C}-\boldsymbol{f}_{j}\left(\boldsymbol{S}_{r \Sigma}^{z-1}+\boldsymbol{S}_{e j}^{z}+\Delta \boldsymbol{S}_{r}^{z}\right) \geq \mathbf{0} \quad j \in J, z \in Z
\end{gathered}
$$

Optimal solution of problem (34)-(36) is $\Delta \boldsymbol{S}_{r}^{z^{*}}$. Considering Eqn (33), it becomes clear that components $\Delta \boldsymbol{S}_{r}^{1}, \Delta \boldsymbol{S}_{r}^{2}+\ldots+\Delta \boldsymbol{S}_{r}^{z-1}$ are optimal solutions of separate stages $\Delta \boldsymbol{S}_{r}^{1 *}, \Delta \boldsymbol{S}_{r}^{2 *}+\ldots+\Delta \boldsymbol{S}_{r}^{(z-1)^{*}}$. Residual forces $\boldsymbol{S}_{r}^{z^{*}}=\boldsymbol{S}_{r \Sigma}^{z-1}+\Delta \boldsymbol{S}_{r}^{z^{*}}$ are obtained at the end of each scanning stage and they coincide with optimal solution of the problem (30)-(32) for the same stage. Solution of the dual problem to (34)-(36) consists of $\Theta_{p}^{z *}$ and $\boldsymbol{u}_{r}^{z^{*}}$. Applying Eqns (15) and (16) it is not difficult to check the relation between obtained solutions: $\boldsymbol{S}_{r}^{z^{*}}=\boldsymbol{S}_{r \Sigma}^{z-1}+\Delta \boldsymbol{S}_{r}^{z^{*}}=\overline{\boldsymbol{G}} \boldsymbol{\Theta}_{p}^{z^{*}}$ and $\boldsymbol{u}_{r}^{z^{*}}=\overline{\boldsymbol{H}} \Theta_{p}^{z^{*}}$. Advantage of the problem (34)-(36) is that increments $\Delta \boldsymbol{S}_{r}^{z^{*}}$ are obtained at once at the end of each stage.

\subsection{About unloading phenomenon of cross-sections during shakedown process}

Yield conditions (9) of the analysis problem (7)-(9) which are satisfied as equalities (therefore corresponding plastic multipliers are positive $\lambda>0$ ) are called active yield conditions. Complementary slackness conditions (11), (13), and (14) $\lambda_{j}^{T}\left[\boldsymbol{C}-\boldsymbol{f}_{j}\left(\boldsymbol{S}_{e j}+\boldsymbol{S}_{r}\right)\right]=0$, $\lambda_{j} \geq \mathbf{0}, \boldsymbol{C}-\boldsymbol{f}_{j}\left(\boldsymbol{S}_{e j}+\boldsymbol{S}_{r}\right) \geq \mathbf{0}$ for all $j \in J$ do not allow direct evaluation of unloading phenomenon. Optimal solution $\boldsymbol{S}_{r}^{*}, \boldsymbol{u}_{r}^{*}, \lambda_{j}^{*}$ of the problem (7)-(9) is obtained without analyzing loading history: in this case locus of internal forces $\boldsymbol{S}_{e}(t)$ is represented by vectors $\boldsymbol{S}_{e j}=\boldsymbol{\alpha} \boldsymbol{F}_{j}, j \in J$.

Scanning procedure helps to notice the fact of unloading phenomenon of cross-sections. By solving analysis problems (30)-(32) or (34)-(36), it is possible to determine cross-sections where unloading phenomenon from variation of active yield conditions appeared (if once active condition $C_{i, j}-f_{i, j}\left(\boldsymbol{S}_{e i, j}+\boldsymbol{S}_{r i}\right)=0$ became inactive $\left.C_{i, j}-f_{i, j}\left(\boldsymbol{S}_{e i, j}+\boldsymbol{S}_{r i}\right)>0\right)$. Naturally, choice of one or the other scanning tactics (Fig. 2) has a significant influence on determination of fact of unloading phenomenon.

\section{Determination of plastic deformation growth}

Example 2. Scanning procedure is illustrated with mathematical model (34)-(36) of analysis problem for frame shown in Figure 1. Frame is subjected to variable repeated loads $0 \leq F_{1}(t) \leq 341.0 \mathrm{kN}$ and $0 \leq F_{2}(t) \leq 440.0 \mathrm{kN}$. Four scanning stages $z=1,2, \ldots, \eta=4$ will be performed. Note that for $z=1, \Delta \boldsymbol{S}_{r}^{0}=\mathbf{0}$ and $\boldsymbol{S}_{r \Sigma}^{0}=\mathbf{0}$. There is only one effective load combination $\boldsymbol{F}_{j=1}^{z=1}=\left[\begin{array}{ll}341.0 & 0\end{array}\right]^{T}$ for the first stage $(z=1)$. For the second stage $z=2$, the first load combination $j=1$ allows us to write vector $\boldsymbol{F}_{j=1}^{z=2}=\left[\begin{array}{ll}341.0 & 0\end{array}\right]^{T}$, the second one $j=2$ gives $\boldsymbol{F}_{j=2}^{z=2}=\left[\begin{array}{ll}0 & 398.3159\end{array}\right]^{T}$ and the third one $(j=3)$ $\boldsymbol{F}_{j=3}^{z=2}=\left[\begin{array}{ll}341.0 & 398.3159\end{array}\right]^{T}$. Then elastic forces $\boldsymbol{S}_{e j}^{z}$ can be determined according to Eqn (29).

Load variation bounds are selected to highlight variation of plastic deformations in different sections, i.e. to determine formal transition of plastic deformations from non-zero to zero (unloading phenomenon) and their variation from zero to the final value. Such load variation bounds can be obtained, for example, by solving analysis problem (30)-(32).

The results of scanning problem (34)-(35) are presented for each stage of scanning process in Table 2. From Table 2, it is possible to see that plastic deformations $\Theta_{p 7}^{(z=1)}=0.001389$ appeared in the 5th section at the first scanning stage $z=1$. Meanwhile, if the second stage $z=2$ would be performed at once, plastic deformations $\Theta_{p, 14}^{(z=2)}=-0.001889$ would appear only in the 10th section, and we even wouldn't know, that plastic deformations $\Theta_{p 7}=0.001389$ could have been in the 5 th section. Thus, the fact that the 5 th section had experienced unloading was recorded.

At the stage $z=3$, plastic deformation of the 10th section continued developing $\Theta_{p, 14}^{(z=3)}=-0.00539$ and new plastic deformations appeared in the 9th section $\left(\Theta_{p, 13}^{(z=3)}=-8.60 E-09\right)$. Residual forces $\boldsymbol{S}_{r}^{(z=4)}$ obtained at the end of stage $z=4$ completely coincide with optimal solution $\boldsymbol{S}_{r}^{*}$ of the problem (7)-(9) presented in Table 1 (for the same set of forces).

We will show that actual plastic deformations can be determined without ignoring the unloading for each stage, i.e. taking into account influence of deformations of the first stage $(z=1)$ to results of further scanning stages. Values of actual plastic deformations $\tilde{\boldsymbol{\Theta}}_{p}^{(z)}$ and total residual forces $\tilde{\boldsymbol{S}}_{r \Sigma}^{(z)}$ resulted by those deformations are presented in Table 3.

Calculation of actual plastic deformations $\tilde{\boldsymbol{\Theta}}_{p}^{(z)}$ (see Table 3), what remains after unloading of cross-section, is explained in details. Having performed scanning stage $z=2$, it is noticed that the 5th section experienced unloading: yield condition is not violated (satisfied as strict inequality), but plastic deformation $\Theta_{p, 7}=0.001389$ remains for structure at stage $z=2$ as well. Meanwhile, vector of plastic deformations $\Theta_{p}^{(z=2)}$, presented in Table 2, contains only one non-zero component $\Theta_{p, 14}^{(z=2)}=-0.001886$. Recalculation of this deformation is performed taking into account unloading of cross-section. We need to find actual component of plastic deformations $\tilde{\Theta}_{p, m}^{(z=2)}$, where $m=14$, taking into account deformation $\tilde{\Theta}_{p, n}^{(z=2)}=\Theta_{p, 7}=0.001389$ (here $n=7$ ), which we don't see at stage $z=2$ anymore. Equations are created 


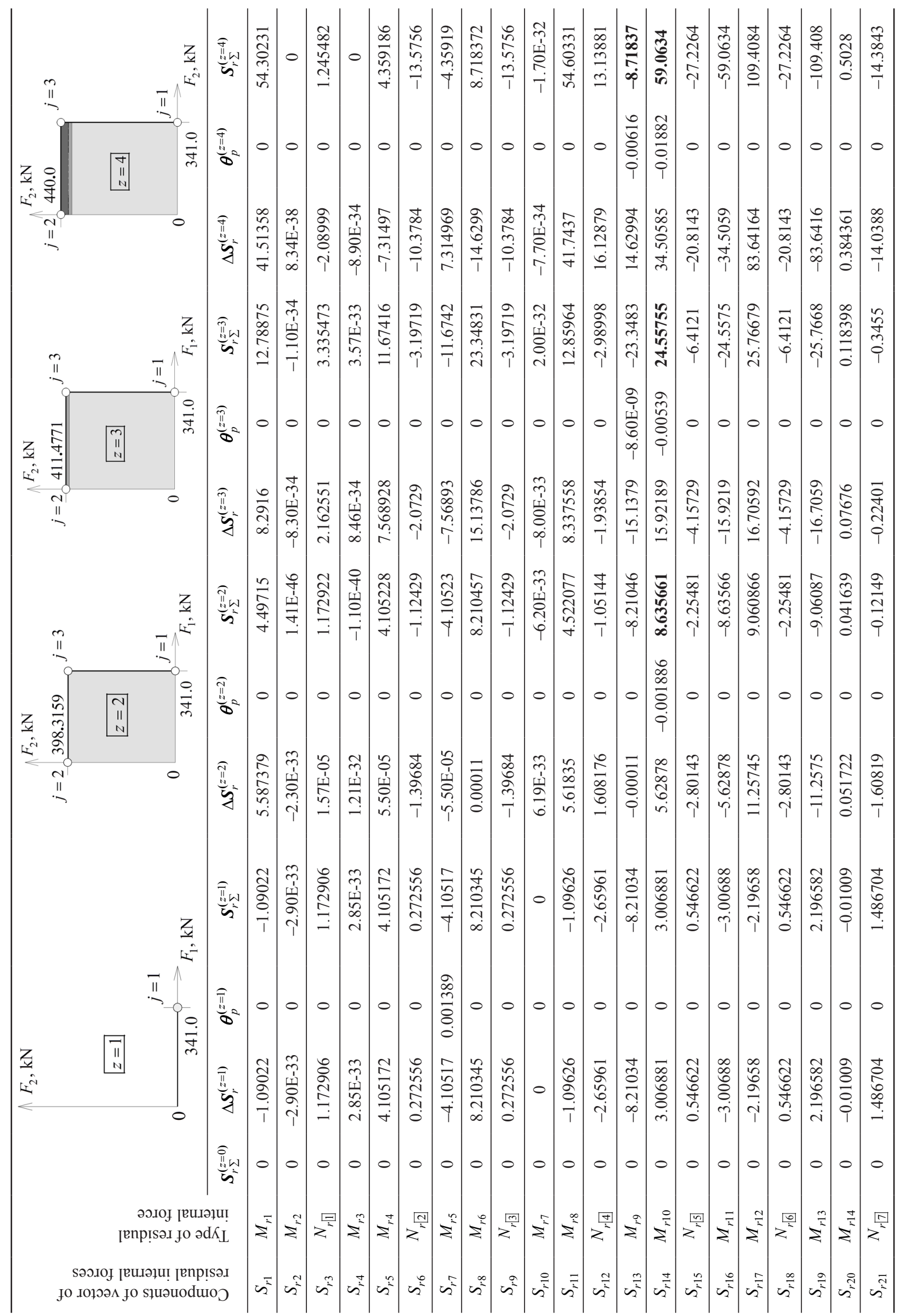


Table 3. Actual plastic deformations $\tilde{\boldsymbol{\Theta}}_{p}^{(z)}$ and residual internal forces $\tilde{\boldsymbol{S}}_{r \Sigma}^{(z)}$

\begin{tabular}{cccccccc}
\hline $\begin{array}{c}\text { Components of } \\
\text { residual forces }\end{array}$ & $\begin{array}{c}\text { Type of } \\
\text { residual force }\end{array}$ & $\tilde{\boldsymbol{\Theta}}_{p}^{(z=2)}$ & $\tilde{\boldsymbol{S}}_{r \Sigma}^{(z=2)}$ & $\tilde{\boldsymbol{\Theta}}_{p}^{(z=3)}$ & $\tilde{\boldsymbol{S}}_{r \Sigma}^{(z=3)}$ & $\tilde{\boldsymbol{\Theta}}_{p}^{(z=4)}$ & $\tilde{\boldsymbol{S}}_{r \Sigma}^{(z=4)}$ \\
\hline$S_{r 1}$ & $M_{r 1}$ & 0 & 1.841049 & 0 & 10.13261 & 0 & 54.30232 \\
\hline$S_{r 2}$ & $M_{r 2}$ & 0 & $-3.90 \mathrm{E}-35$ & 0 & $-9.80 \mathrm{E}-34$ & 0 & 0 \\
\hline$S_{r 3}$ & $N_{r[1}$ & 0 & 1.937425 & 0 & 4.099985 & 0 & 1.245481 \\
\hline$S_{r 4}$ & $M_{r 3}$ & 0 & $-4.60 \mathrm{E}-32$ & 0 & $5.79 \mathrm{E}-34$ & 0 & 0 \\
\hline$S_{r 5}$ & $M_{r 4}$ & 0 & 6.780987 & 0 & 14.34995 & 0 & 4.359184 \\
\hline$S_{r 6}$ & $N_{r[2}$ & 0 & -0.46026 & 0 & -2.53315 & 0 & -13.5756 \\
\hline$S_{r 7}$ & $M_{r 5}$ & 0.001389 & $-\mathbf{6 . 7 8 0 9 9}$ & 0.001389 & $-\mathbf{1 4 . 3 4 9 9}$ & 0.001389 & $-\mathbf{4 . 3 5 9 1 8}$ \\
\hline$S_{r 8}$ & $M_{r 6}$ & 0 & 13.56197 & 0 & 28.69989 & 0 & 8.718368 \\
\hline$S_{r 9}$ & $N_{r[3}$ & 0 & -0.46026 & 0 & -2.53315 & 0 & -13.5756 \\
\hline$S_{r 10}$ & $M_{r 7}$ & 0 & $9.93 \mathrm{E}-32$ & 0 & $1.65 \mathrm{E}-31$ & 0 & $-1.00 \mathrm{E}-31$ \\
\hline$S_{r 11}$ & $M_{r 8}$ & 0 & 1.851255 & 0 & 10.18878 & 0 & 54.60332 \\
\hline$S_{r 12}$ & $N_{r[4]}$ & 0 & -3.34494 & 0 & -5.28351 & 0 & 13.13881 \\
\hline$S_{r 13}$ & $M_{r 9}$ & 0 & -13.562 & 0 & -28.6999 & -0.0068496 & $-\mathbf{8 . 7 1 8 3 7}$ \\
\hline$S_{r 14}$ & $M_{r 10}$ & -0.001236 & $\mathbf{8 . 6 3 5 6 6 1}$ & -0.004732 & $\mathbf{2 4 . 5 5 7 5 5}$ & -0.018820 & $\mathbf{5 9 . 0 6 3 4}$ \\
\hline$S_{r 15}$ & $N_{r[5]}$ & 0 & -0.92308 & 0 & -5.08035 & 0 & -27.2264 \\
\hline$S_{r 16}$ & $M_{r 11}$ & 0 & -8.63566 & 0 & -24.5575 & 0 & -59.0634 \\
\hline$S_{r 17}$ & $M_{r 12}$ & 0 & 3.70935 & 0 & 20.4152 & 0 & 109.4084 \\
\hline$S_{r 18}$ & $N_{r[6}$ & 0 & -0.92308 & 0 & -5.08035 & 0 & -27.2264 \\
\hline$S_{r 19}$ & $M_{r 13}$ & 0 & -3.70935 & 0 & -20.4152 & 0 & -109.408 \\
\hline$S_{r 20}$ & $M_{r 14}$ & 0 & 0.017045 & 0 & 0.093811 & 0 & 0.502789 \\
\hline$S_{r 21}$ & $N_{r[7}$ & 0 & 1.407518 & 0 & 1.183527 & 0 & -14.3843 \\
\hline & & 0 & & 0 & 0 & 0 \\
\hline
\end{tabular}

according to following technique of component selection: we pick the member from influence matrix of residual forces $\overline{\boldsymbol{G}}$, which is in row $m$ and column $n$, i.e. $\bar{G}(m, n)$, and the member from vector $\boldsymbol{S}_{r \Sigma}^{(z=2)}$ (see Table 2) in the position of $(m)$ component, i.e. $S_{r \Sigma, m}^{(z=2)}$ :

$$
\bar{G}(14,7) \cdot \Theta_{p, 7}+\bar{G}(14,14) \cdot \tilde{\Theta}_{p, 14}^{(z=2)}=S_{r \Sigma, 14}^{(z=2)} .
$$

In other words, having recalculated $\Theta_{p, 14}^{(z=2)}$ and obtained actual component $\widetilde{\Theta}_{p, 14}^{(z=2)}$, influence of unloaded plastic deformations $\Theta_{p, 7}$ to residual force $S_{r \Sigma, 14}^{(z=2)}$ is evaluated.

Thus, we solve Eqn (37):

$$
\begin{aligned}
& \bar{G}(14,7) \cdot 0.001389+\bar{G}(14,14) \cdot \tilde{\Theta}_{p, 14}^{(z=2)}=8.63566 ; \\
& 2165.14 \cdot 0.001389-4554.53 \cdot \tilde{\Theta}_{p, 14}^{(z=2)}=8.63566 \\
& \tilde{\Theta}_{p, 14}^{(z=2)}=\frac{8.63566-2165.14 \cdot 0.001389}{-4554.53}=-0.001236 .
\end{aligned}
$$

That way vector of actual plastic deformations $\tilde{\Theta}_{p}^{(z=2)}$ is formed, taking into account unloaded deformations $\Theta_{p, 7}=0.001389$ (see Table 3):

$$
\begin{aligned}
& \tilde{\Theta}_{p}^{(z=2)}=\left[\begin{array}{llllllllllll}
0 & 0 & 0 & 0 & 0 & 0 & 0.001389 & 0 & 0 \\
0 & 0 & 0 & 0 & -0.001236 & 0 & 0 & 0 & 0 & 0 & 0 & 0
\end{array}\right]^{T} .
\end{aligned}
$$

Similarly, at stage $z=3$, component $\tilde{\Theta}_{p, 14}^{(z=3)}$ of actual plastic deformation vector $\tilde{\Theta}_{p}^{(z=3)}$ is determined from following equation:

$$
\bar{G}(14,7) \cdot \Theta_{p, 7}+\bar{G}(14,14) \cdot \tilde{\Theta}_{p, 14}^{(z=3)}=S_{r \Sigma, 14}^{(z=3)} .
$$

It is obtained $\tilde{\Theta}_{p, 14}^{(z=3)}=-0.004732$, i.e. actual plastic deformation, taking into account unloaded deformations $\Theta_{p, 7}=0.001389$, what were at stage $z=1$. The result is vector $\tilde{\Theta}_{p}^{(z=3)}$ (see Table 3).

Here plastic deformations should not be confused with their increments, what are determined during transi- 
tion, for example, from stage $z=2$ to $z=3$, i.e. increment $\Delta \tilde{\Theta}_{p, 14}^{(z=3)}$ is found as follows:

$$
\begin{aligned}
& \bar{G}(14,7) \cdot \Theta_{p, 7}+\bar{G}(14,14) \cdot \tilde{\Theta}_{p, 14}^{(z=2)}+ \\
& \bar{G}(14,14) \cdot \Delta \tilde{\Theta}_{p, 14}^{(z=3)}=S_{r \Sigma, 14}^{(z=3)} .
\end{aligned}
$$

Then

$$
\begin{aligned}
& \tilde{\Theta}_{p, 14}^{(z=3)}=\tilde{\Theta}_{p, 14}^{(z=2)}+\Delta \tilde{\Theta}_{p, 14}^{(z=3)}= \\
& -0.001236-0.003496=-0.004732 .
\end{aligned}
$$

At the last stage $z=4$, vector of actual plastic deformations $\tilde{\Theta}_{p}^{(z=4)}$ is formed after solving following equation system:

$$
\left\{\begin{array}{l}
\bar{G}(13,7) \cdot \Theta_{p, 7}+\bar{G}(13,13) \cdot \tilde{\Theta}_{p, 13}^{(z=4)}+ \\
\bar{G}(13,14) \cdot \tilde{\Theta}_{p, 14}^{(z=4)}=S_{r \Sigma, 13}^{(z=4)} \\
\bar{G}(14,7) \cdot \Theta_{p, 7}+\bar{G}(14,13) \cdot \tilde{\Theta}_{p, 13}^{(z=4)}+ \\
\bar{G}(14,14) \cdot \tilde{\Theta}_{p, 14}^{(z=4)}=S_{r \Sigma, 14}^{(z=4)} .
\end{array}\right.
$$

Then $\tilde{\Theta}_{p, 13}^{(z=4)}=-0.0068496$ and $\tilde{\Theta}_{p, 14}^{(z=4)}=-0.018820$ are obtained. And the vector of actual plastic deformations for stage $z=4$ is formed as follows:

$$
\begin{aligned}
& \tilde{\Theta}_{p}^{(z=4)}=\left[\begin{array}{llllllllllllll}
0 & 0 & 0 & 0 & 0 & 0 & 0.001389 & 0 & 0 & 0 & 0 \\
0 & -0.0068496 & -0.018820 & 0 & 0 & 0 & 0 & 0 & 0 & 0
\end{array}\right]^{T} .
\end{aligned}
$$

Vectors of forces $\boldsymbol{S}_{r \Sigma}^{(z=2)}, \boldsymbol{S}_{r \Sigma}^{(z=3)}$ and $\boldsymbol{S}_{r \Sigma}^{(z=4)}$ presented in Table 3 are obtained by solving extreme problem (27)-(28) for each distribution of actual plastic deformations $\tilde{\boldsymbol{\Theta}}_{p}^{(z=2)}, \tilde{\boldsymbol{\Theta}}_{p}^{(z=3)}$ and $\tilde{\boldsymbol{\Theta}}_{p}^{(z=4)}$ separately.

Let's stress statement of Melan's theorem: at shakedown, the dependence of residual forces $\boldsymbol{S}_{r}$ on loading history is not valid for unloaded sections (in this case for the 9th and the 10th sections), like it is shown in Table 3.

In the Example 1, following vector of residual displacements $\boldsymbol{u}_{r}^{*}=\overline{\boldsymbol{H}} \Theta_{p}^{*}, \mathrm{~m}$ is obtained at shakedown:

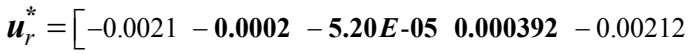

$$
\begin{aligned}
& -0.00997-0.00426-0.00561-1.60 E-06-0.00563-\mathbf{0 . 0 0 0 5 3} \\
& -0.00564-\mathbf{1 . 0 E - 0 5}-0.005680 .025925-0.005711 .88 E-05]^{T} \text {. }
\end{aligned}
$$

In the Example 2, for $\tilde{\boldsymbol{\Theta}}_{p}^{(z=4)}$ (see Table 3), the other vector of residual displacements $\tilde{\boldsymbol{u}}_{r}=\overline{\boldsymbol{H}} \tilde{\boldsymbol{\Theta}}_{p}^{(z=4)}, \mathrm{m}$ is determined:

$$
\begin{aligned}
& \tilde{\boldsymbol{u}}_{r}=\left[\begin{array}{lllll}
-0.0021 & \mathbf{0 . 0 0 0 4 9 5} & \mathbf{0 . 0 0 0 6 4 3} & \mathbf{- 0 . 0 0 0 3} & -0.00212
\end{array}\right. \\
& \begin{array}{llllll}
-0.00997 & -0.00426 & -0.00561 & -1.60 E-06 & -0.00563 & \mathbf{0 . 0 0 1 9 0 3}
\end{array} \\
& -0.00564-\mathbf{1 . 7 0 E - 0 5}-0.005680 .025925-0.00571 \quad 1.88 E-05]^{T} \text {. }
\end{aligned}
$$

We see that some components of vectors $\boldsymbol{u}_{r}^{*}$ and $\tilde{\boldsymbol{u}}_{r}$ are different, for example $\boldsymbol{u}_{r 3}^{*}=-5.20 E-05 \mathrm{~m}$, but $\tilde{\boldsymbol{u}}_{r 3}=0.000643 \mathrm{~m}$. It is obvious that this difference between components of residual displacement vectors will have influence for defining variation bounds $\boldsymbol{u}_{r, \text { sup }}$ and $\boldsymbol{u}_{r, \text { inf }}$ of displacements. It is important to note, that both of the vectors $\boldsymbol{u}_{r}^{*}$ and $\tilde{\boldsymbol{u}}_{r}$ represents the state of shakedown. Therefore definition of bounds $\boldsymbol{u}_{r, \text { sup }}$ and $\boldsymbol{u}_{r, \text { inf }}$ is crucial for checking the serviceability requirements when solving shakedown optimization problems.

\section{Conclusions}

1. Residual displacements of structures at shakedown depend on loading history.

2. For structures which cross-sections experience unloading during shakedown process, the principle of total potential energy minimum should not be directly applied for determination of residual displacements.

3. Scanning technique enables registering unloading phenomenon only within limits of chosen strategy. Reliability of determining variation bounds of residual displacements can be increased by increasing number of strategies.

4. In contrast to traditional "step by step" methods, the proposed technique does not require to change design scheme for each scanning strategy.

5. Presented technique enables precise implementation of structural safety and serviceability requirements (by estimating the variation bounds of the residual displacements $\boldsymbol{u}_{r, \text { sup }}$ and $\boldsymbol{u}_{r, \text { inf }}$ ) in mathematical models of optimization at shakedown problems.

\section{References}

Alawdin, P.; Liepa, L. 2016. Shakedown optimization of the thin-wall metal structures under strength and stiffness constrains, Chapter 45, in Proceedings of the XIII International Conference on Metal Structures - Recent Progress in Steel and Composite Structures, 2016, Leiden, Netherlands: CRC Press/Balkema, 393-400. http://dx.doi.org/10.1201/b21417-54

Alawdin, P.; Liepa, L. 2015. Optimal shakedown analysis of plane reinforced concrete frames according to Eurocodes, International Journal of Mechanics and Materials in Design. 14 p. http://dx.doi.org/10.1007/s10999-015-9331-0

Alawdin, P.; Kasabutski, S. 2009. Limit and shakedown analysis of RC rod cross-sections, Journal of Civil Engineering and Management 15(1): 59-66. http://dx.doi.org/10.3846/1392-3730.2009.15.59-66

Alawdin, P. 2005. Predelnyy analiz konstruktsiy pri povtornykh nagruzheniyakh [Limit analysis of structures under variable loads]. Minsk: Tekhnoprint (in Russian).

Atkočiūnas, J.; Ulitinas, T.; Kalanta, S.; Blaževičius, G. 2015. An extended shakedown theory on an elastic-plastic spherical shell, Engineering Structures 101: 352-363. http://dx.doi.org/10.1016/j.engstruct.2015.07.021

Atkočiūnas, J. 2012. Optimal shakedown design of elastic-plastic structures. Vilnius: Technika. http://dx.doi.org/10.3846/1240-S

Atkočiūnas, J.; Venskus, A. 2011. Optimal shakedown design of frames under stability conditions according to standards, Computers \& Structures 89(3-4): 435-443. http://dx.doi.org/10.1016/j.compstruc.2010.11.014

Bazaraa, M. S.; Sherali, H. D.; Shetty, C. M. 2006. Nonlinear programming: theory and algorithms. Wiley-Interscience. http://dx.doi.org/10.1002/0471787779 
Belytschko, T. 1972. Plane stress shakedown analysis by finite elements, International Journal of Mechanical Sciences 14(9): 619-625. http://dx.doi.org/10.1016/0020-7403(72)90061-6

Capurso, M. 1974. A displacement bounding principle in shakedown of structures subjected to cyclic loads, International Journal of Solids and Structures 10(1): 77-92. http://dx.doi.org/10.1016/0020-7683(74)90102-4

Casciaro, R.; Garcea, G. 2002. An iterative method for shakedown analysis, Computer Methods in Applied Mechanics and Engineering 191(49-50): 5761-5792. http://dx.doi.org/10.1016/S0045-7825(02)00496-6

Chaaba, A.; Bousshine, L.; De Saxce, G. 2010. Kinematic limit analysis of nonassociated perfectly plastic material by the bipotential approach and finite element method, Journal of Applied Mechanics 77(3), no 031016. 11 p. http://dx.doi.org/10.1115/1.4000383

EN 1993-1-1:2005 Design of steel structures Part 1-1: General rules and rules for buildings. European Standard.

Giambanco, F.; Palizzolo, L.; Caffarelli, A. 2004. Computational procedures for plastic shakedown design of structures, Structural and Multidisciplinary Optimization 28(5): $317-$ 329. http://dx.doi.org/10.1007/s00158-004-0402-3

Kala, Z. 2005. Sensitivity analysis of the stability problems of thin-walled structures, Journal of Constructional Steel Research 61(3): 415-422. http://dx.doi.org/10.1016/j.jcsr.2004.08.005

Kalanta, S.; Atkočiūnas, J; Venskus, A. 2009. Discrete optimization problems of the steel structures, Engineering Structures 31(6): 1298-1304.

http://dx.doi.org/10.1016/j.engstruct.2009.01.004

Kalanta, S.; Atkočiūnas, J; Ulitinas, T. 2012. The discrete model and the analysis of a spherical shell by finite equilibrium elements, Mechanika 18(3): 266-272.

http://dx.doi.org/10.5755/j01.mech.18.3.1886

Kaliszky, S.; Lógó, J. 2002. Plastic behaviour and stability constraints in the shakedown analysis and optimal design of trusses, Structural and Multidisciplinary Optimization 24(2): 118-124. http://dx.doi.org/10.1007/s00158-002-0222-2

Koiter, W. T. 1960. General theorems for elastic-plastic solids, in I. Sheddon, R. Hills (Eds.). Progress in solid mechanics. North-Holland, Amsterdam, 165-221.

König, J. A. 1987. Shakedown of elastic-plastic structures, fundamental studies in engineering. Elsevier Science Ltd.

Lange-Hansen, P. 1998. Comparative study of upper bound methods for the calculation of residual deformations after shakedown. Institut for Bærende Konstruktioner og Materialer, Danmarks Tekniske Universitet.

Liepa, L.; Gervyte, A. 2015. Residual displacement analysis of structures at shakedown, in Proc. of the Fifteenth International Conference on Civil, Structural and Environmental Engineering Computing, paper 250.

http://dx.doi.org/10.4203/ccp.108.250
Maier, G. 1969. Shakedown theory in perfect elastoplasticity with associated and nonassociated flow-laws: a finite element, linear programming approach, Meccanica 4(3): 250-260. http://dx.doi.org/10.1007/BF02133439

McGuire, W.; Gallagher, R. H.; Ziemian, R. D. 2000. Matrix structural analysis. $2^{\text {nd }}$ ed. New York: John Wiley and Sons Publishers.

Merkevičiūtè, D.; Atkočiūnas, J. 2006. Optimal shakedown design of metal structures under stiffness and stability constraints, Journal of Constructional Steel Research 62(12): 1270-1275. http://dx.doi.org/10.1016/j.jcsr.2006.04.020

Ngo, N. S.; Tin-Loi, F. 2007. Shakedown analysis using the $p$ adaptive finite element method and linear programming, Engineering Structures 29: 46-56. http://dx.doi.org/10.1016/j.engstruct.2006.03.033

Palizzolo, L.; Caffarelli, A.; Tabbuso, P. 2014. Minimum volume design of structures with constraints on ductility and stability, Engineering Structures 68: 47-56. http://dx.doi.org/10.1016/j.engstruct.2014.02.025

Polizzotto, C.; Borino, G.; Caddemi, S.; Fuschi, P. 1991. Shakedown problems for material models with internal variables, European Journal of Mechanics - A/Solids 10(6): 621-639.

Raad, L.; Weichert, D. 1995. Stability of pavement structures under long term repeated loading, in Z. Mroz, D. Weichert, S. Dorosz (Eds.). Inelastic behaviour of structures under variable loads. Springer Netherlands, 473-496.

Rozvany, G. I. N. 2011. Structural design via optimality criteria: The Prager approach to structural optimization. Kluwer Academic Publishers.

Simon, J.-W.; Kreimeier, M.; Weichert, D. 2013. A selective strategy for shakedown analysis of engineering structures, International Journal for Numerical Methods in Engineering 94(11): 985-1014. http://dx.doi.org/10.1002/nme.4476

Staat, M.; Heitzer, M. (Eds.). 2003. Publication series of the John von Neumann Institute for computing. NIC Series Volume 15. Jülich: NIC-Directors.

Stein, E.; Zhang, G.; König, J. A. 1992. Shakedown with nonlinear strain-hardening including structural computation using finite element method, International Journal of Plasticity 8(1): 1-31. http://dx.doi.org/10.1016/0749-6419(92)90036-C

Tran, T. N. 2011. A dual algorithm for shakedown analysis of plate bending, International Journal for Numerical Methods in Engineering 86(7): 862-875. http://dx.doi.org/10.1002/nme.3081

Venskus, A.; Kalanta, S.; Atkočiūnas, J.; Ulitinas, T. 2010. Integrated load optimization of elastic-plastic axisymmetric plates at shakedown, Journal of Civil Engineering and Management 16(2): 203-208. http://dx.doi.org/10.3846/jcem.2010.22

Weichert, D.; Maier, G. (Eds.). 2002. Inelastic behaviour of structures under variable repeated loads. Vienna: Springer Vienna. http://dx.doi.org/10.1007/978-3-7091-2558-8

Liudas LIEPA. He is PhD Student of Structural engineering at the Department of Structural Mechanics (VGTU). Research interests: structural and computational mechanics, shakedown theory, optimization and analysis of geometrically nonlinear structures, applied mathematical programming.

Gediminas BLAŽEVIČIUS. Dr, Assistant lecturer at the Department of Structural Mechanics, Vilnius Gediminas Technical University. His research interests include nonlinear analysis, optimization and optimal shakedown design of structural systems.

Dovilė MERKEVIČIŪTĖ. Dr, Associate Professor at the Department of Structural Mechanics (VGTU). Research interest: optimization of geometrically non-linear elastic-plastic structures at shakedown.

Juozas ATKOČIŪNAS. Prof. Dr Habil, Head of the Department of Structural Mechanics at VGTU. Civil engineer (1967). Dr Eng (structural mechanics, 1973). Dr Habil (mechanics, 1996). Research interests: optimal shakedown design of elastic-plastic structures, structural and computational mechanics, applied mathematical programming. 